Corrosion Characterization of Iron-Based High-Performance Amorphous-Metal Thermal-Spray Coatings

J. C. Farmer, J. J. Haslam, S. D. Day, D. J. Branagan, C. A. Blue, J. D. K. Rivard, L. F. Aprigliano, N. Yang, J. H. Perepezko, M. B. Beardsley

March 21, 2005

ASME Pressure Vessels \& Piping Division Conference Denver, CO, United States July 17, 2005 through July 21, 2005 
This document was prepared as an account of work sponsored by an agency of the United States Government. Neither the United States Government nor the University of California nor any of their employees, makes any warranty, express or implied, or assumes any legal liability or responsibility for the accuracy, completeness, or usefulness of any information, apparatus, product, or process disclosed, or represents that its use would not infringe privately owned rights. Reference herein to any specific commercial product, process, or service by trade name, trademark, manufacturer, or otherwise, does not necessarily constitute or imply its endorsement, recommendation, or favoring by the United States Government or the University of California. The views and opinions of authors expressed herein do not necessarily state or reflect those of the United States Government or the University of California, and shall not be used for advertising or product endorsement purposes. 


\author{
American Society of Mechanical Engineers \\ Pressure Vessels \& Piping (PVP) Conference - July 2005
}

\title{
CORROSION CHARACTERIZATION OF IRON-BASED HIGH-PERFORMANCE AMORPHOUS-METAL THERMAL-SPRAY COATINGS
}

\author{
J. C. Farmer ${ }^{1}$, J. J. Haslam ${ }^{1}$, S. D. Day ${ }^{1}$, D. J. Branagan², C. A. Blue ${ }^{3}$, J. D. K. Rivard ${ }^{3}$, L. F. \\ Aprigliano ${ }^{4}$, N. Yang ${ }^{5}$, J. H. Perepezko ${ }^{6}$ and M. B. Beardsley ${ }^{7}$ \\ Lawrence Livermore National Laboratory ${ }^{1}$, NanoSteel Company ${ }^{2}$, Oak Ridge National Laboratory ${ }^{3}$, \\ Naval Surface Warfare Center ${ }^{4}$, Sandia National Laboratory California ${ }^{5}$, \\ University of Wisconsin Madison ${ }^{6}$ and Caterpillar ${ }^{7}$
}

This work was performed under the auspices of the U.S. Department of Energy by University of California Lawrence Livermore National Laboratory under contract No. W-7405-Eng-48.

\begin{abstract}
New corrosion-resistant, iron-based amorphous metals have been identified from published data or developed through combinatorial synthesis, and tested to determine their relative corrosion resistance. Many of these materials can be applied as coatings with advanced thermal spray technology. Two compositions have corrosion resistance superior to wrought nickel-based Alloy C-22 (UNS \# N06022) in some very aggressive environments, including concentrated calcium-chloride brines at elevated temperature. One of these compositions, SAM1651, is discussed in detail to illustrate the promise of this general class of materials.
\end{abstract}

\section{INTRODUCTION}

Corrosion costs the Department of Defense billions of dollars every year, with an immense quantity of material in various structures undergoing corrosion. For example, in addition to fluid and seawater piping, ballast tanks, and propulsions systems, approximately 345 million square feet of structure aboard naval ships and crafts require costly corrosion control measures. The use of advanced corrosion-resistant materials to prevent the continuous degradation of this massive surface area would be extremely beneficial. The Fe-based corrosion-resistant, amorphous-metal coatings under development may prove of importance for applications on ships. The possible advantages of amorphous metals has been recognized for some time [Latanison 1985]

Such materials could also be used to coat the entire outer surface of containers for the transportation and long-term storage of spent nuclear fuel, or to protect welds and heat affected zones, thereby preventing exposure to environments that might cause stress corrosion cracking [Farmer et al. 2000 a $\& 2000$ b]. In the future, it may be possible to substitute such high-performance iron-based materials for more-expensive nickel-based alloys, thereby enabling cost savings in various industrial applications.

\section{MATERIALS DESIGN AND SYNTHESIS}

Objectives. This project has three primary longterm goals, all directed towards development of advanced amorphous-metal thermal-spray coatings with corrosion resistance superior to: (1) Type 316L stainless steel [UNS \# S31603], (2) nickel-based Alloy C-22 [UNS \# N06022], and (3) Ti Grade 7 (UNS \# R52400). Computational materials science has been used to help guide the design these new materials [Kaufman 2004; Farmer et al. 2004].

Thermal Spray Processes. A wide variety of thermal spray processes have been developed by industry. These processes include: flame spray, wirearc; plasma spray; water-stabilized plasma spray; high-velocity oxy-fuel; and the detonation gun. Any of these can be used for the deposition of the formulations discussed here, with varying degrees of residual porosity and crystallinity.

Flame Spray Process (FSP). The FSP uses a combustion flame, and characterized by relatively low gas and particle velocities. Typical metallic coatings produced with this process include $\mathrm{Ni}-\mathrm{Fe}-\mathrm{Al}$ compositions. These coatings have bond strengths of about 4,000 pounds per square inch, porosities of approximately 5 percent (5\%), and micro-hardness of $85 \mathrm{HRB}$.

Wire Arc Process (WAP). The WAP uses an electrical discharge instead of a combustion flame, and is more energetic than FSP. Typical metallic coatings produced with this process include $67 \% \mathrm{FE}$ $28 \% \mathrm{Cr} 5 \% \mathrm{C}$ compositions. These coatings have bond strengths of about 5,800 pounds per square inch, porosities of approximately two percent $(2 \%)$, and micro-hardness of $55 \mathrm{HRC}$. 


\section{American Society of Mechanical Engineers Pressure Vessels \& Piping (PVP) Conference - July 2005}

Plasma Spray Process (PSP). The PSP involves the use of and electric arc with inert gas to create a plasma. Flame temperatures as high as $30,000^{\circ} \mathrm{C}$ can be achieved. These coatings have bond strengths of about 8,000 pounds per square inch, porosities of approximately three percent $(3 \%)$, and microhardness of $90 \mathrm{HRB}$.

High Velocity Oxy Fuel (HVOF) Process. The conventional HVOF process also involves a combustion flame, and is characterized by gas and particle velocities that are three to four times the speed of sound (mach 3 to 4). This process is ideal for depositing metal and cermet coatings, including chromium carbide with a nickel-chromium binder. These coatings have bond strengths of about 8,600 pounds per square inch, porosities of less than one percent $(<1 \%)$, and micro-hardness of $68 \mathrm{HRC}$.

Water Stabilized Plasma Spray Process (WSPSP). The WS-PSP has been recently developed by Caterpillar, and provides the capability of spraying at extremely high rates, approaching 200 pounds per hour. This process has already been used for coating large components.

Laser Assisted Plasma Spray Process (LA-PSP). The LA-PSP involves the direct interaction of a highintensity laser beam with spray particles and the substrate. This process has been to produce metallic coatings with virtually theoretical density, and with metallurgical bonding. In regard to the distribution of energy released during the process, ninety to ninetyfive percent $(90-95 \%)$ of the energy is transferred from the plasma torch to the spray powder, and used to melt the powder, while five to ten percent $(5-10 \%)$ of the energy is consumed by the laser, and ultimately used to fuse the spray particles, and to melt the substrate.

Detonation Gun Process (DGP). The DGP was developed in Russia and is based upon the discontinuous detonation of an oxygen-fuel mixture. Very high gas and particle velocities are achieved with this novel process, with velocities approaching four to five times the speed of sound (mach 4-5). This process is also ideal for depositing metal and cermet coatings. Coatings have been made with exceptional bond strengths, in excess of 10,000 psi, porosities of less than 0.5 percent $(<0.5 \%)$, and micro-hardness of 68 HRC.

Corrosion Resistant Compositions with Theoretical Density. The development of an appropriate powder composition for the production of a corrosion-resistant thermal-spray coating requires that the alloy first be tested in a form with no porosity, and with little or no crystalline phases present. Testing of such materials enables determination of the best possible corrosion performance for a given composition. Melt spinning and arc-melting with drop casting have been used as a methods to synthesize completely amorphous, Febased, corrosion-resistant alloys with near theoretical density, thereby enabling the effects of coating morphology on corrosion resistance to be separated from the effects of elemental composition.

Cooling rates as great as one billion Kelvin per second $\left(10^{9} \mathrm{~K} / \mathrm{s}\right)$ have been achieved. In contrast, the cooling rate in a typical thermal spray process such as HVOF are on the order of ten thousand Kelvin per second $\left(10^{4} \mathrm{~K} / \mathrm{s}\right)$. The melt-spun ribbons produced with this equipment are several meters long, several millimeters wide, and approximately 150 microns thick.

Melt Spinning Process. The melt spinning involves the ejection of a liquid melt onto a rapidly moving copper wheel with a pressure-controlled gas. The liquid melt solidifies onto the wheel, with subsequent separation from the wheel by thermal contraction and centrifugal force, and collection in a chamber. By changing the tangential velocity of the wheel, as well as other processing parameters, the cooling rate can be controlled over a very broad range. The specific processing parameters for the melt-spinning process can be selected to establish cooling rates that are representative of a given thermal spray process. If a specific cooling rate produces an amorphous, glassy metal during melt spinning, it should also produce a glassy structure during thermal spray. It is therefore possible to use melt spinning to simulate the type of microstructure that can be achievable with thermal spraying, such as the high-velocity oxy-fuel process. Furthermore, an entire series of developmental materials, with different compositions, heat capacities, and thermal conductivity, can be made with the exact same cooling rate, thereby enabling materials scientists and engineers to determine the relative ease of processing.

Several alloy compositions of Fe-based amorphous metals have been produced, characterized, and tested [Farmer et al. 2005]. In principle, all were intended to be compositional modifications of the SAM40 parent material, obeying the following the general formula: $\left[(\mathrm{SAM} 40)_{100-\mathrm{x}}+\right.$ $Y_{x}$ ] where $Y$ is the added element, and $x$ is the amount of the addition in atomic percent. Additives investigated included nickel, chromium, molybdenum, tungsten, yttrium, titanium and zirconium. The nickel and molybdenum additions are known to greatly influence the electrochemical properties of conventional stainless steel alloys [Asphahani 1980]. The yttrium, titanium, and zirconium additions, while not normally added to steels are known to form very stable oxides and are expected to increase the stability and passivity of the 


\section{American Society of Mechanical Engineers Pressure Vessels \& Piping (PVP) Conference - July 2005}

oxide film in a variety of environments. These materials have been selected with particular emphasis on glass forming ability, thermal stability, hardness, and corrosion resistance, all under conditions of interest [Farmer et al. 2004].

The melt-spinning process was used to perform a systematic study of various elemental compositions, each based on the Fe-based SAM40 composition, with 1, 3, 5, and 7 atomic percent additions of specific elements believed to be beneficial to glass formation or corrosion resistance. Elemental additions investigated included nickel, molybdenum, yttrium, titanium, zirconium, and chromium. The densities of the amorphous metals prepared with melt spinning were determined, and all were less dense than nickel-based N06022 (Alloy C-22), and therefore offer a weight advantage over such classical corrosion-resistant alloys. The first re-crystallization peak for each of melt-spun ribbons was determined with DTA, and was similar to that of the parent material (SAM40). The formula with the yttrium additions showed re-crystallization peaks at higher temperatures than achieved with other formulae, showing that yttrium additions do indeed promote thermal stability and glass formability. Some formulae exhibited a second re-crystallization process at a higher temperature than the first, with titanium and zirconium based formulations showing these processes at the highest temperatures. All of the "ascast" amorphous metal formulae produced by the HPCRM Team exhibited hardness far superior to many of the conventional materials of interest, such as Type $316 \mathrm{~L}$ stainless steel, and nickel-based N06022 (Alloy C-22). Thus, coatings of these materials would also be expected to be less prone to erosion, wear and gouging than conventional engineering alloys. Partially de-vitrified samples of the HPCRM materials exhibited dramatic increases in hardness. Thus, carefully controlled heat treatment of these materials can be used to achieve dramatic improvements in resistance to erosion, wear and penetration.

Arc Melting with Drop Casting. In addition to the melt-spinning process, arc-melted drop-cast ingots of a wide variety of Fe-based amorphous metals were synthesized for corrosion testing. These ingots were cast into cylindrical molds, thus forming long rods with a nominal diameter of 2-3 millimeters. By exploring the findings of Poon et al. [2004], it has been learned that additions of 2-3 atomic percent yttrium or zirconium can enhance the glass-forming ability (GFA), and substantially lower the required critical cooling rate (CCR). Such formulations are relatively easily cast as large-diameter (several millimeter) rods. The X-ray diffraction (XRD) pattern for drop-cast ingot of SAM1651 was determined at Sandia National Laboratory, and is presented in Figure 1 [Yang et al. 2004]. It shows virtually no crystalline structure. Peak broadening of all three HVOF coatings suggest presence of some fine crystalline phases in the amorphous matrix. Figure 2 shows the onset of devitrification of the SAM1651 and SAM40 parent material at $800^{\circ} \mathrm{C}$. From the electron backscatter images in Figure 3, the advantages of rare earth additions are evident. The exact composition of this material, which has also been produced as melt-spun ribbon, is published elsewhere [Farmer et al. 2004].

Optimization of the thermal spray process through careful selection of powder size and process temperature, has now yielded coatings of SAM40 (non-optimized elemental coating) that are virtually pore-free, and for all practical purposes, fully dense. These new coating architectures have also been shown, through detailed examination with XRD and SEM, to be amorphous. During the fall of FY05, the new SAM2X5 and SAM1651 will be rendered as fully dense, pore-free, amorphous metal coatings for corrosion testing, using the optimized thermal spray process.

\section{THERMAL PROPERTIES}

In addition to having enhanced corrosion resistance, these new Fe-based amorphous metals have substantially improved thermal characteristics, which will improve processing ability, and performance in targeted applications, as shown by the University of Wisconsin at Madison [Perepezko et al. 2004; Farmer et al. 2004]. While there was some sample-to-sample variability, results were generally consistent For example, SAM2X5 has a glass transition temperature of $\sim 579^{\circ} \mathrm{C}$, a recrystallization temperature of $\sim 628^{\circ} \mathrm{C}$, a melting point of $\sim 1133^{\circ} \mathrm{C}$, and a reduced glass transition temperature of $\sim 0.57$ (with a value of 0.6 being ideal). SAM2X7, an alloy in the same family as SAM2X5, has a glass transition temperature of $\sim 573^{\circ} \mathrm{C}$, a recrystallization temperature of $\sim 630^{\circ} \mathrm{C}$, a melting point of $\sim 1137^{\circ} \mathrm{C}$, and a reduced glass transition temperature of 0.57 . Similarly, SAM1651 has a glass transition temperature of $\sim 584^{\circ} \mathrm{C}$, a recrystallization temperature of $\sim 653^{\circ} \mathrm{C}$, a melting point of $\sim 1121^{\circ} \mathrm{C}$, and a reduced glass transition temperature of $\sim 0.55$. The critical cooling rates for SAM2X7 and SAM1651, have been determined to be $\sim 610$ and $\leq$ $80 \mathrm{~K}$ per second, respectively. Clearly, the yttrium additions in SAM1651 enhance glass-forming ability, as reported by Guo and Poon [2003]. 


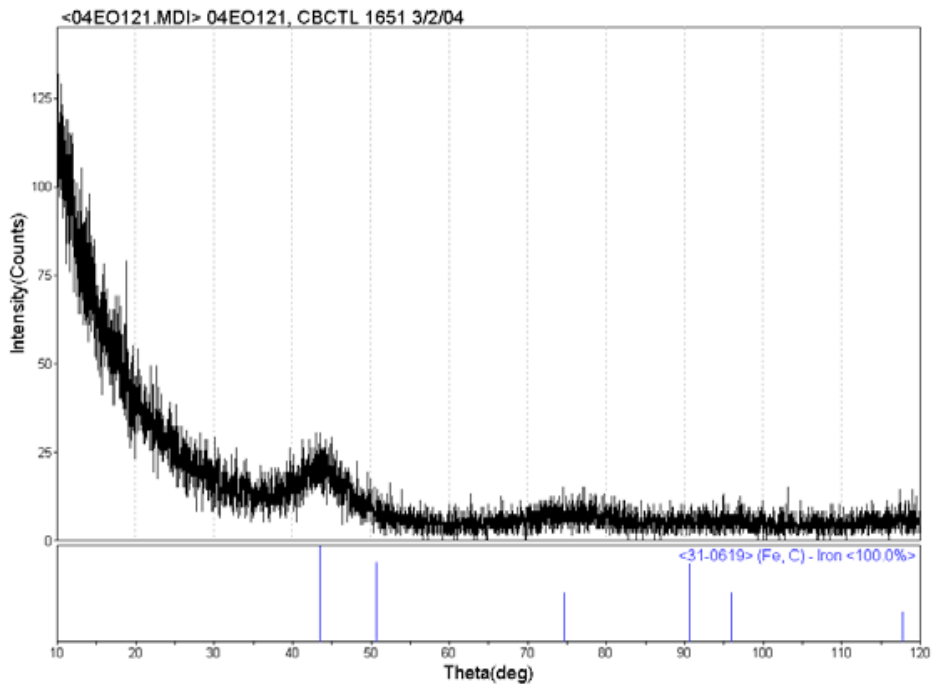

Figure 1 - X-ray diffraction pattern for drop-cast ingot of SAM1651, that shows virtually no crystalline structure. Peak broadening of all three HVOF coatings suggest presence of some fine crystalline phase(s) in the amorphous matrix.

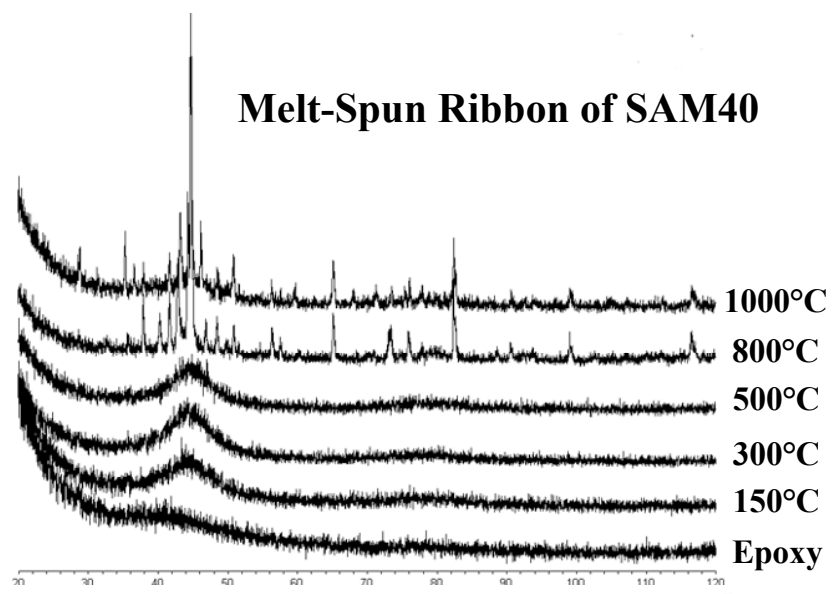

\section{Drop-Cast Ingot of SAM1651}

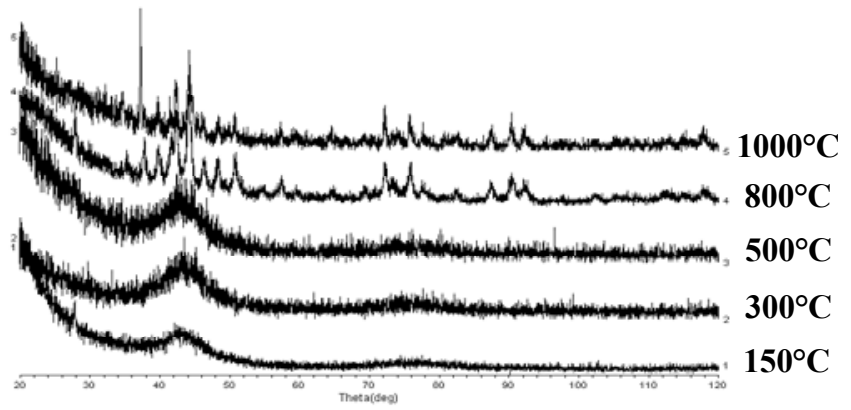

Figure 2 - X-ray diffraction (XRD) shows that the matrices of melt-spun ribbons of SAM40 parent material and drop-cast ingots of SAM1651 remain amorphous to $500^{\circ} \mathrm{C}$. However, XRD is not effective for detecting dispersed crystalline phase(s) that account for less than 2 volume $\%$ of the material. Electron microscopy was used to compensate for this shortcoming. 


\section{American Society of Mechanical Engineers \\ Pressure Vessels \& Piping (PVP) Conference - July 2005}
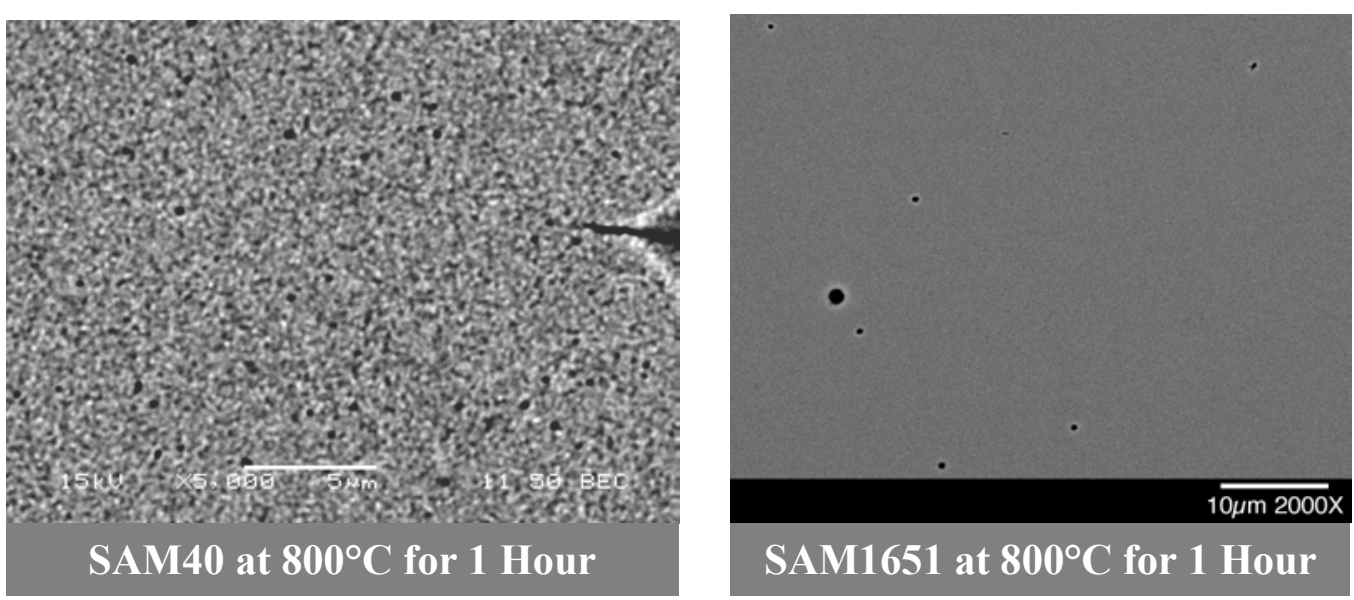

Figure 3 - Back-scattered electron (BEI) images of the SAM40 parent material and SAM1651 show that the Ycontaining variant has better thermal stability at high temperature, which corroborates the work published by Guo and Poon [2003].

\section{AQUEOUS PHASE CORROSION}

Electrochemical Testing. Cyclic polarization (CP) is used as a means of measuring the critical potential $\left(E_{\text {critical }}\right)$ of corrosion resistant materials, relative to their open-circuit corrosion potential $\left(E_{c o r r}\right)$. Spontaneous breakdown of the passive film and localized corrosion require that the open-circuit corrosion potential exceed the critical potential:

$$
E_{\text {corr }} \geq E_{\text {critical }}
$$

In the published scientific literature, different bases exist for determining the critical potential from electrochemical measurements. Some have defined the critical potential for crevice corrosion of Alloy 22 as the point where the current density increases to 1 to $10 \mu \mathrm{A} / \mathrm{cm}^{2}\left(10^{-6}\right.$ to $\left.10^{-5} \mathrm{~A} / \mathrm{cm}^{2}\right)$ during the forward (anodic) scan, whereas others define the repassivation potential as the point where the current density drops to 0.1 to $1 \mu \mathrm{A} / \mathrm{cm}^{2}\left(10^{-6}\right.$ to $\left.10^{-7} \mathrm{~A} / \mathrm{cm}^{2}\right)$, and use the repassivation potential as a conservative estimate of the critical value [Farmer et al. 2000a].

Cyclic polarization measurements have been based on a procedure similar to ASTM G-5, with slight modification [American Society for Testing and Materials]. For example, ASTM G-5 calls for an electrolyte of $1 \mathrm{~N}_{2} \mathrm{SO}_{4}$, whereas natural seawater, synthetic bicarbonate brines, synthetic sulfatechloride brines, $4 \mathrm{M} \mathrm{NaCl}$ solutions, and $5 \mathrm{M} \mathrm{CaCl}_{2}$ solutions with various levels of nitrate were used in this study. The compositions of the synthetic brines are given in the literature [Farmer et al. 2000]. Furthermore, ASTM G-5 calls for the use of deaerated solutions, whereas aerated and de-aerated solutions were used here. After a 24-hour hold period, during which the open circuit corrosion potential is determined, the potential is scanned in the positive (anodic) direction from a level slightly more negative than the corrosion potential (cathodic limit), to a reversal potential $\left(E_{\text {rev }}\right)$ near that required for oxygen evolution (anodic level). During the positive scan, anodic oxidation peaks may be observed (centered at $E_{\text {peak }}$ ) that have been correlated with the oxidation of molybdenum at the alloy surface (passive film), as well as current excursions that are usually associated with catastrophic breakdown of the passive film. During the negative (cathodic) scan, a hysteresis loop will be observed in cases where passivity has been lost. As the scan continues, the current density may eventually decrease to a level equivalent to that experienced during the positive scan, and indicative of reformation of the passive film. The potential at which this occurs is known as the repassivation potential $\left(E_{r p}\right)$.

A temperature-controlled, borosilicate glass (Pyrex), electrochemical cell was used. This cell had three electrodes, a working electrode (test specimen), the reference electrode, and the counter electrode. A standard silver silver-chloride electrode, filled with near-saturation potassium chloride solution, was used as the reference, and communicated with the test solution via a Luggin probe placed in close proximity to the working electrode, thereby minimizing Ohmic losses. Numerical corrections for the reference electrode junction potential have been estimated, and have been found to be insignificant (Farmer et al. 2000). The electrochemical cell was equipped with a water-cooled junction to maintain reference electrode at ambient temperature, thereby maintaining integrity 


\section{American Society of Mechanical Engineers Pressure Vessels \& Piping (PVP) Conference - July 2005}

of the potential measurement, and a water-cooled condenser to prevent the loss of volatile species from the electrolyte.

Critical-Potential Concept. The resistance to localized corrosion is quantified through measurement of the open-circuit corrosion potential $\left(\mathrm{E}_{\text {corr }}\right)$, the breakdown potential $\left(\mathrm{E}_{\text {crit }}\right)$ and the repassivation potential $\left(\mathrm{E}_{\mathrm{rp}}\right)$. The greater the difference between the open-circuit corrosion potential and the repassivation potential $(\Delta \mathrm{E})$, the more resistant a material is to modes of localized corrosion such a pitting and crevice corrosion.

Competing methodologies exist for the interpretation of experimental data in terms of the critical potential $\left(E_{c r i t}\right)$. Method A strives to identify the potential where the passive film disappears during the forward (anodic) potential scan. The loss of passivity is indicated by a sudden, dramatic increase in the measured current density. The current density corresponding to a complete loss of passivity is assumed to be approximately 20 or $200 \mu \mathrm{A} / \mathrm{cm}^{2}$. The breakdown potential may be the best estimate of the true critical potential, since it corresponds to the onset of passive film destabilization. Methods B and $\mathrm{C}$ strive to identify the potential where the passive film reappears during the negative (cathodic) potential scan. Repassivation is indicated by a sudden, precipitous decrease in the measured current density, to levels indicative of an intact passive film. Method $\mathrm{C}$ relies on no arbitrary threshold, and is therefore preferred.

- Method A - Initial Breakdown of Passive Film

○ Critical Potential $\left(E_{\text {crit }}\right)=$ Breakdown

Potential (E20 or E200)

- Based Threshold Current Density of 20 or $200 \mu \mathrm{A} / \mathrm{cm}^{2}$

- Method B - Repassivation of Surface

- Critical Potential $\left(E_{\text {crit }}\right)=$ Repassivation Potential (ER1 or ER2)

O Based Threshold Current Density of 1 or 2 $\mu \mathrm{A} / \mathrm{cm}^{2}$

- Method C - Repassivation of Surface

○ Critical Potential $\left(E_{\text {crit }}\right)=$ Repassivation Potential (ERP)

- Intersection of Forward Scan with Hysteresis Loop (Cross-Over Point)

Figure 4 shows an actual cyclic polarization curve for Alloy $\mathrm{C}-22$ in $5 \mathrm{M} \mathrm{CaCl}_{2}$ at $105^{\circ} \mathrm{C}$, with three methodologies illustrated for determining the threshold potential for the initiation of localized corrosion in performance assessment models. Method
A is based upon the critical potential at which the passive film breaks down (current excursion, 2 or 20 $\mu \mathrm{A} / \mathrm{cm}^{2}$ ). Method B is based upon the repassivation potential, which in turn is based upon an arbitrary threshold ( 1 or $2 \mu \mathrm{A} / \mathrm{cm}^{2}$ ). Method $\mathrm{C}$ is based upon the repassivation potential, determined from the intersection of the hysteresis loop with the forward scan, and is preferred.

Passive film stability, quantified through such electrochemical testing, is strongly dependent upon the environment. Cyclic polarization curves for wrought Alloy $\mathrm{C}-22$ (N06022) in $5 \mathrm{M} \mathrm{CaCl} 2$ in $105^{\circ} \mathrm{C}$, and in seawater at $90^{\circ} \mathrm{C}$, are compared in Figure 5 . The test in seawater shows only a very small hysteresis loop, and a relatively high repassivation potential, indicative of good resistance to localized attack. The test in calcium chloride shows a very large hysteresis loop, and a relatively low repassivation potential of between -150 to -200 $\mathrm{mV}$ vs. $\mathrm{Ag} / \mathrm{AgCl}$. These data indicate that Alloy C-22 has relatively poor resistance to localized corrosion in concentrated calcium chloride brines at elevated temperature.

A premise of this research is that the corrosionresistance of Fe-based amorphous metals can be improved by systematic addition of alloying elements such as chromium, molybdenum, and tungsten, all of which are known to enhance passive film stability. Such elemental additions account for the observed difference in the corrosion resistance of Type $316 \mathrm{~L}$ stainless steel, and nickel-based C-22 (alloy N06022).

\section{HOT CALCIUM CHLORIDE ENVIRONMENTS}

Cyclic polarization testing of reference materials such as Alloy C-22 and various Fe-based amorphous metals were conducted in $5 \mathrm{M} \mathrm{CaCl}_{2}$ at $105^{\circ} \mathrm{C}$. Data for wrought nickel-based Alloy C-22 (N06022) and iron-based SAM1651 amorphous metal ingot are compared in Figure 6. The data for Alloy C-22 show a catastrophic breakdown of the passive film at 100 $\mathrm{mV}$, which causes a very large hysteresis loop. During the reverse scan, repassivation occurs at a relatively low potential ( -150 to $-200 \mathrm{mV}$ vs. $\mathrm{Ag} / \mathrm{AgCl})$. These data indicate that Alloy C-22 has relatively poor resistance to localized corrosion in the test environment. In sharp contrast to Alloy C-22, the SAM1651 ingot showed no breakdown of the passive film, even at potentials approaching that required for oxygen evolution. It is therefore concluded that the corrosion resistance of the amorphous metal is superior to that of Alloy C-22 in hot concentrated calcium chloride solution. 


\section{Pressure Vessels \& Piping (PVP) Conference - July 2005}

Cyclic polarization data for a wide range of alloy compositions in hot calcium chloride are summarized in Figure 7. The SAM8 formulation uses SAM1651 (Y-containing, high-Mo Fe-based amorphous metal) as the parent material, with the addition of tungsten at 3 atomic percent. The repassivation potential for SAM8 in this aggressive environment (300-400 $\mathrm{mV}$ vs. $\mathrm{Ag} / \mathrm{AgCl}$ ) is substantially higher than that for
Alloy C-22 (-100 mV vs. Ag/AgCl). The SAM6 formulation has the same nominal elemental composition as the P-containing Fe-based amorphous metal formulation discussed in the literature by Pang et al. [2002]. The repassivation potential for SAM6 in this aggressive environment $(400 \mathrm{mV}$ vs. $\mathrm{Ag} / \mathrm{AgCl})$ is substantially higher than that for Alloy C-22 (-100 $\mathrm{mV}$ vs. $\mathrm{Ag} / \mathrm{AgCl})$.

Wrought C-22 (\#4001) in 5M CaCl2 at $105^{\circ} \mathrm{C}$

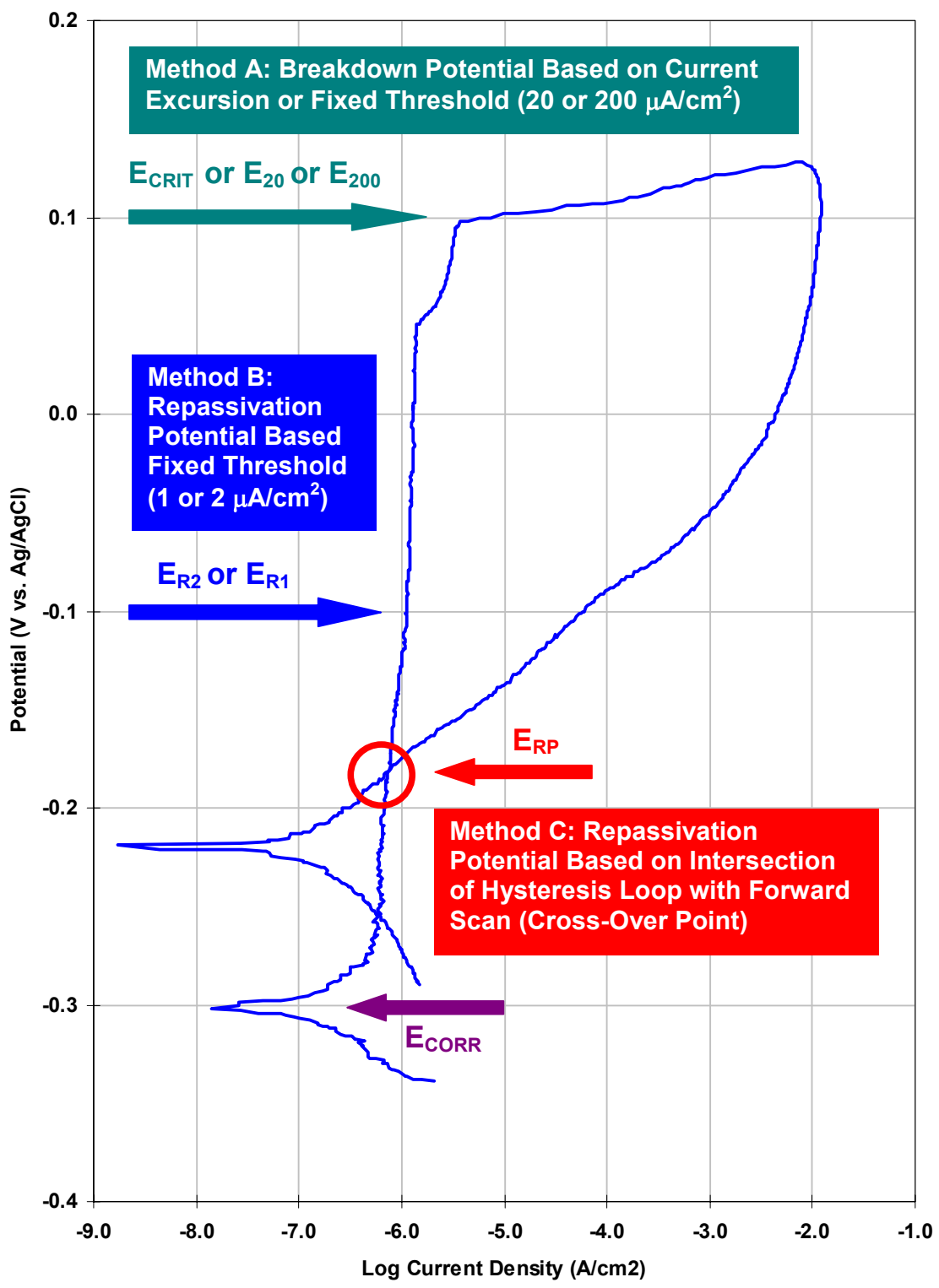

Figure $4-$ This is an actual cyclic polarization curve for Alloy $\mathrm{C}-22$ in $5 \mathrm{M} \mathrm{CaCl}_{2}$ at $105^{\circ} \mathrm{C}$, showing three methodologies for determining the threshold potential for the initiation of localized corrosion in performance assessment models. Method A is based upon the critical potential at which the passive film breaks down (current excursion, 2 or $20 \mu \mathrm{A} / \mathrm{cm}^{2}$ ). Method B is based upon the repassivation potential, which in turn is based upon an arbitrary threshold ( 1 or $2 \mu \mathrm{A} / \mathrm{cm}^{2}$ ). Method $\mathrm{C}$ is based upon the repassivation potential, determined from the intersection of the hysteresis loop with the forward scan. 


\section{C-22 in Seawater at $90^{\circ} \mathrm{C} \& 5 \mathrm{M} \mathrm{CaCl}_{2}$ at $105^{\circ} \mathrm{C}$ CP JE1594 SW $90^{\circ} \mathrm{C} \& \mathrm{JE} 15955 \mathrm{M} \mathrm{CaCl}_{2} 105^{\circ} \mathrm{C}$ Alloy 22}

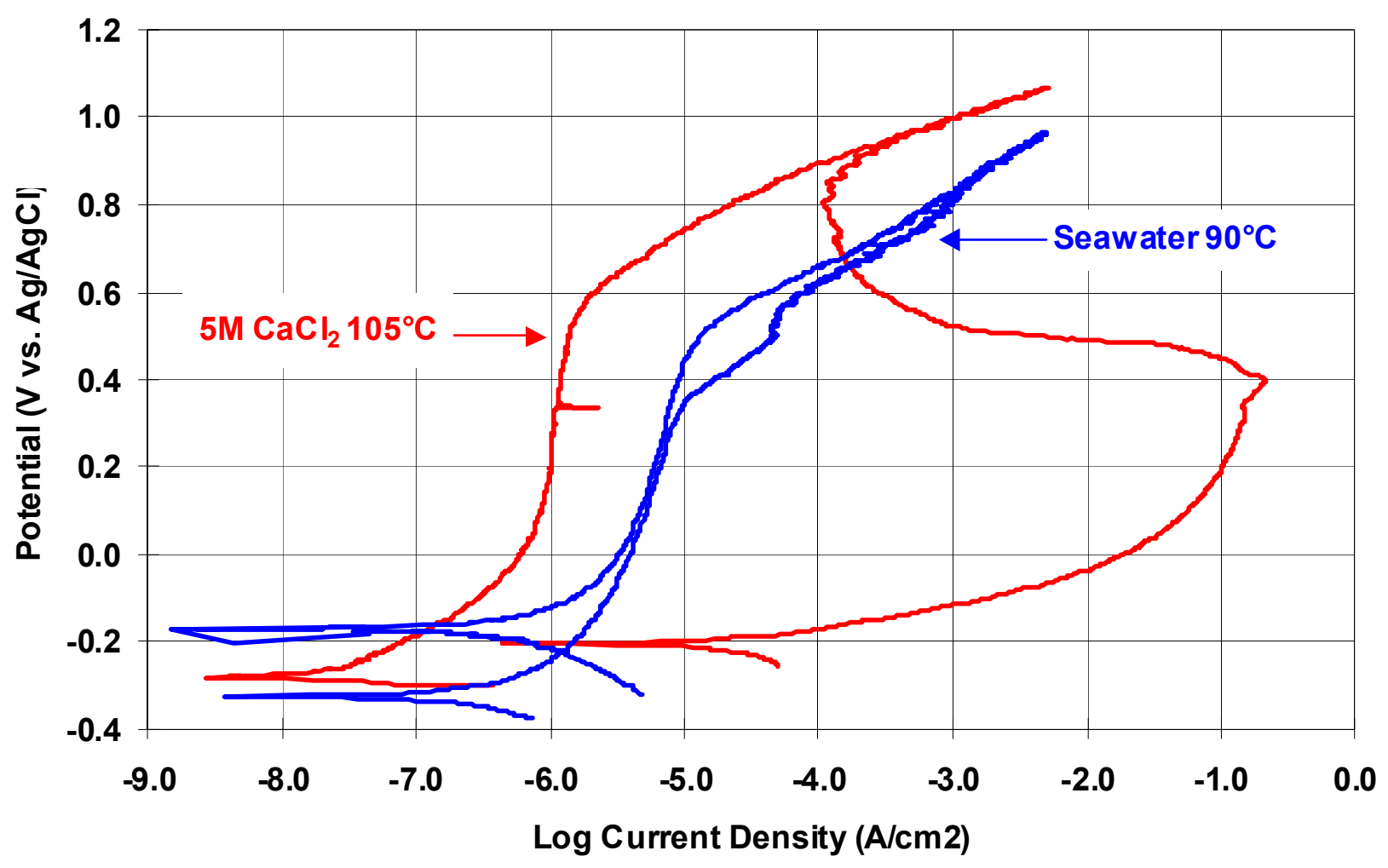

Figure 5 - Cyclic polarization of wrought Alloy C-22 (N06022) in seawater at $90^{\circ} \mathrm{C}$ and in $5 \mathrm{M} \mathrm{CaCl}_{2}$ in $105^{\circ} \mathrm{C}$. The test in seawater shows only a very small hysteresis loop, and a relatively high repassivation potential, indicative of good resistance to localized attack. The test in calcium chloride shows a very large hysteresis loop, and a relatively low repassivation potential of between -150 to $-200 \mathrm{mV}$ vs. $\mathrm{Ag} / \mathrm{AgCl}$. These data indicate that Alloy C-22 has relatively poor resistance to localized corrosion in concentrated calcium chloride brines at elevated temperature. 
American Society of Mechanical Engineers

Pressure Vessels \& Piping (PVP) Conference - July 2005

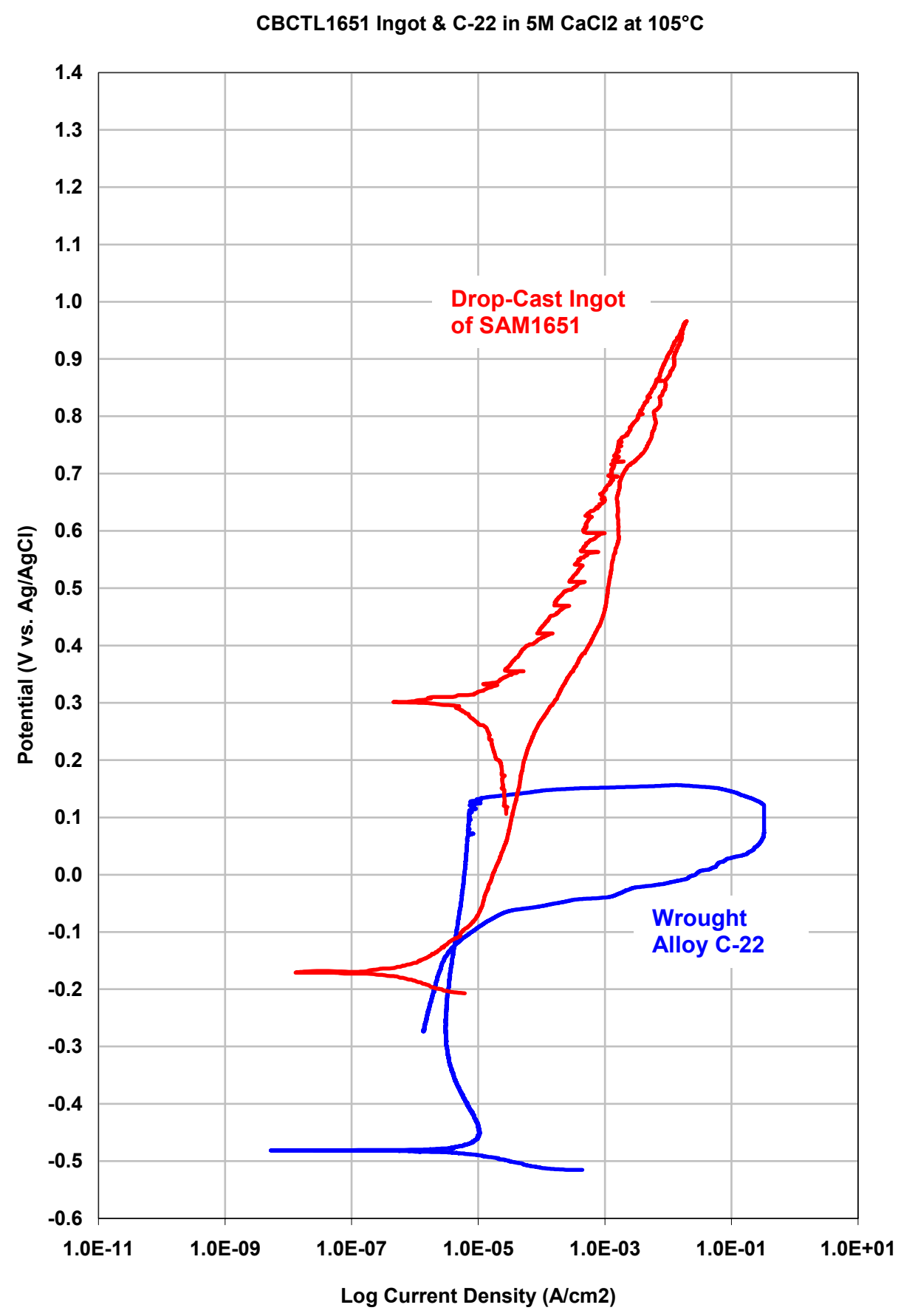

Figure 6 - Cyclic polarization of wrought nickel based Alloy C-22 (N06022) and iron-based amorphous metal (SAM1651) ingot in $5 \mathrm{M} \mathrm{CaCl}_{2}$ at $105^{\circ} \mathrm{C}$. Alloy C-22 shows catastrophic breakdown of the passive film at $100 \mathrm{mV}$ vs. $\mathrm{Ag} / \mathrm{AgCl}$, which causes a very large hysteresis loop. During the reverse scan, repassivation occurs at a relatively low potential $(-150$ to $-200 \mathrm{mV})$. While there was catastrophic breakdown of the Alloy C-22 at very low potential (100 to $200 \mathrm{mV}$ vs. $\mathrm{Ag} / \mathrm{AgCl}$ ), no breakdown of the passive film on SAM1651 ingot was observed, even at potentials approaching that required for oxygen evolution. 


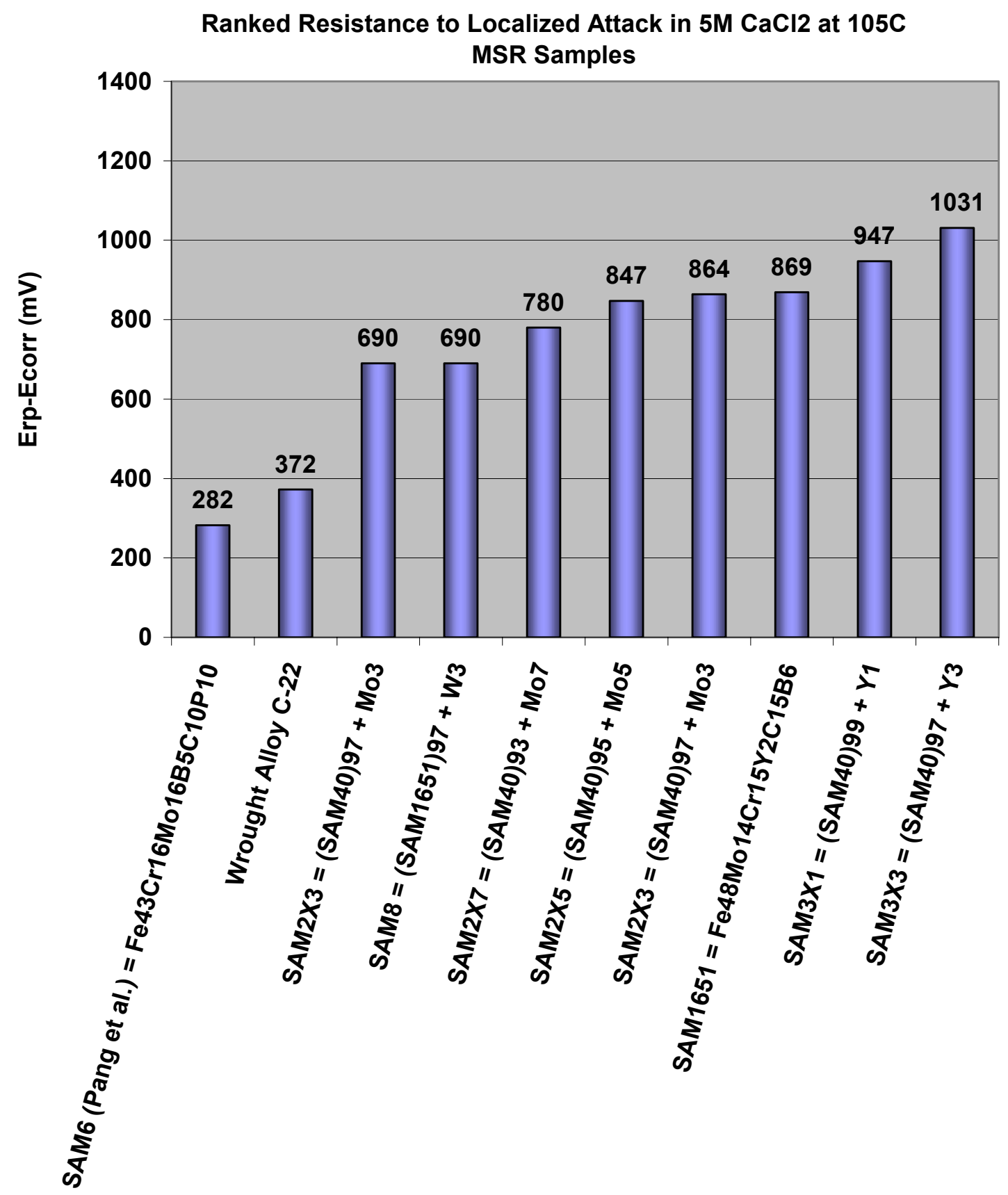

Figure 7 - Various alloy samples, ranked based upon their measured resistance to localized corrosion $(\Delta \mathrm{E}=$ $\mathrm{E}_{\text {corr }}-\mathrm{E}_{\mathrm{rp}}$ ) in $5 \mathrm{M} \mathrm{CaCl}_{2}$ at $105^{\circ} \mathrm{C}$. With the exception of the P-containing Fe-based amorphous metal (Pang et al.), most of the amorphous metals performed very well in this aggressive environment. In contrast, the performance of the wrought nickel-based Alloy C-22 (N06022) was relatively poorly. 


\section{American Society of Mechanical Engineers \\ Pressure Vessels \& Piping (PVP) Conference - July 2005}

\section{SEAWATER \& SALT FOG ENVIRONMENTS}

Electrochemical Testing in Seawater. Cyclic polarization testing of reference materials and Febased amorphous metals were conducted in Half Moon Bay seawater at various temperatures, ranging from 30 to $90^{\circ} \mathrm{C}$, as well as in Key West seawater at ambient temperature. A comparison of the cyclic polarization curves for a SAM1651 amorphous metal ingot, a sample of wrought nickel-based Alloy C-22, and a sample of thermal spray (HVOF) C-22 in ambient temperature Half Moon Bay seawater is shown in Figure 8.

The curves for the SAM1651 ingot and wrought Alloy C-22 have very small hysteresis loops, and repassivation potentials close to the potential required for oxygen evolution. It is therefore concluded that Y-containing Fe-based SAM1651 amorphous metal performs very well in ambient temperature seawater, with performance comparable to wrought Alloy C22. The data in this figure also show that the corrosion resistance of Alloy C-22 is substantially degraded during the thermal spray process.

Figure 9 shows a ranking of various alloy samples, based upon their measured resistance to localized corrosion $\left(\Delta \mathrm{E}=\mathrm{E}_{\text {corr }}-\mathrm{E}_{\mathrm{rp}}\right)$ in Half Moon Bay seawater at $90^{\circ} \mathrm{C}$. Reference samples of Type $316 \mathrm{~L}$ stainless steel do not perform as well in this environment as ingots and melt-spun ribbons of Febased amorphous metals. Most of the amorphoussamples performed very well, with the arc-melted drop-cast ingot of SAM1651 (also designated as SAM7) and other Y-containing variants of the parent material (SAM3X3) showing the best performance. The Mo-containing variants also showed outstanding performance. The previously published P-containing material performed well, but not as well as the $\mathrm{Y}$ - and Mo-containing variants of SAM40 [Pang et al. 2002].

Salt Fog Testing. The salt fog test was used to compare various wrought ant thermal-spray alloys, melt-spun ribbons, arc-melted drop-cast ingots, and thermal-spray coatings for their susceptibility to corrosion by salt sprays, like those that might be encountered aboard naval ships (this test is also known as the "salt spray" test). The most recent tests have focused on refined, state-of-the-art Fe-based amorphous-metal formulations, in the form of arcmelted drop-cast ingots, melt-spun ribbons, and highvelocity oxy-fuel coatings with no significant porosity and near theoretical density. In contrast, the first tests focused on early thermal-spray coatings, which had residual porosity and crystalline structure, and lower resistance to corrosion.

Both salt fog tests were conducted according to ASTM B117 "Standard Test Method of Salt Spray (Fog) Testing." A General Motors (GM) test cycle, GM9540P, was used in both tests. The performance of the test developmental amorphous metal samples was evaluated by qualitative comparison to baseline or reference samples. Four types of reference samples were included to establish baseline performance. These references include: Type 316L stainless steel, nickel-based Alloy C-22 (N06022), Ti Grade 7, and the 50:50 nickel-chromium binary.

During the initial phase of the project, coatings of Type 316L stainless steel, nickel-based Alloy C22, SAM40, SAM40X3 were deposited on stainless steel substrates (Type 316L) with the high-velocity oxy-fuel (HVOF) process. During salt-fog testing, there was no significant rusting of the reference samples. Substantial rusting of early HVOF coatings of SAM40 and Type 316L stainless steel was observed after only 13 cycles. There may have also been some slight rust formation on the Alloy C-22 HVOF coating. The rusting of these early coatings is attributed to non-optimal elemental composition, residual porosity, and partial devitrification during the thermal-spray process.

During the past year, several advanced formulations of Fe-based corrosion-resistant amorphous-metals have been produced. Some of these materials have lower critical cooling rates than the early SAM40 parent material, and may therefore be more easily deposited in a glassy state, and have optimized elemental compositions that exhibit much more stable passive film stability. As illustrated by Figure 10, early thermal-spray coatings of Type 316L stainless steel and the SAM40 parent material showed relatively severe corrosive attack after only 13 cycles in the ASTM B117 salt fog test. However, several of the new Fe-based amorphous metal coatings, including SAM1651 and SAM2X5, have shown no corrosion, even after more than 30 cycles in this aggressive environment. It is therefore believed that these new materials will provide substantial benefit in some Naval applications. 
American Society of Mechanical Engineers

Pressure Vessels \& Piping (PVP) Conference - July 2005

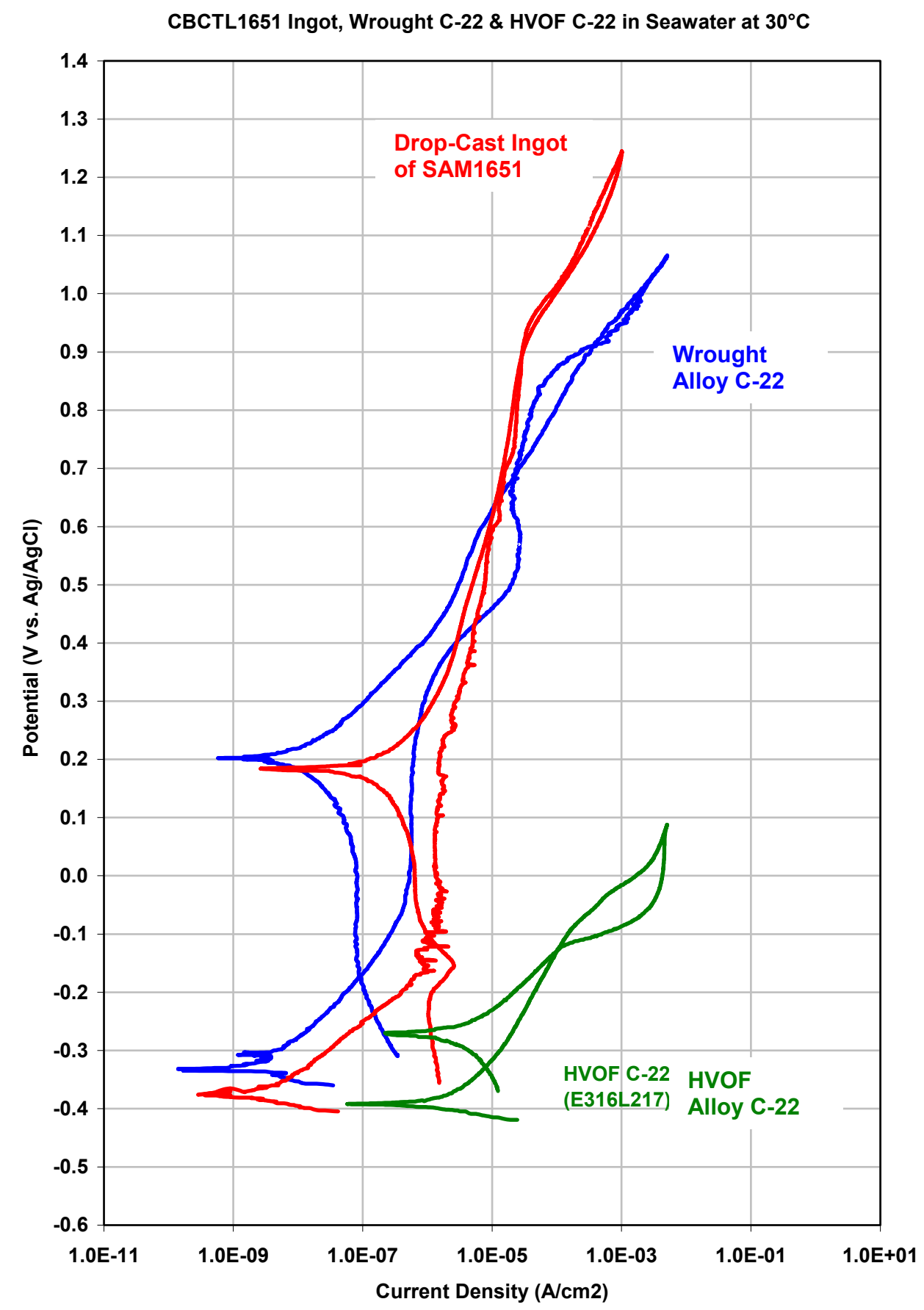

Figure 8 - A comparison of the cyclic polarization curves for a SAM1651 amorphous metal ingot, a sample of wrought nickel-based Alloy C-22, and a sample of thermally spray Alloy C-22 in ambient temperature, Half Moon Bay seawater is shown. The SAM1651 amorphous metal had better corrosion resistance than both wrought and HVOF Alloy C-22. 


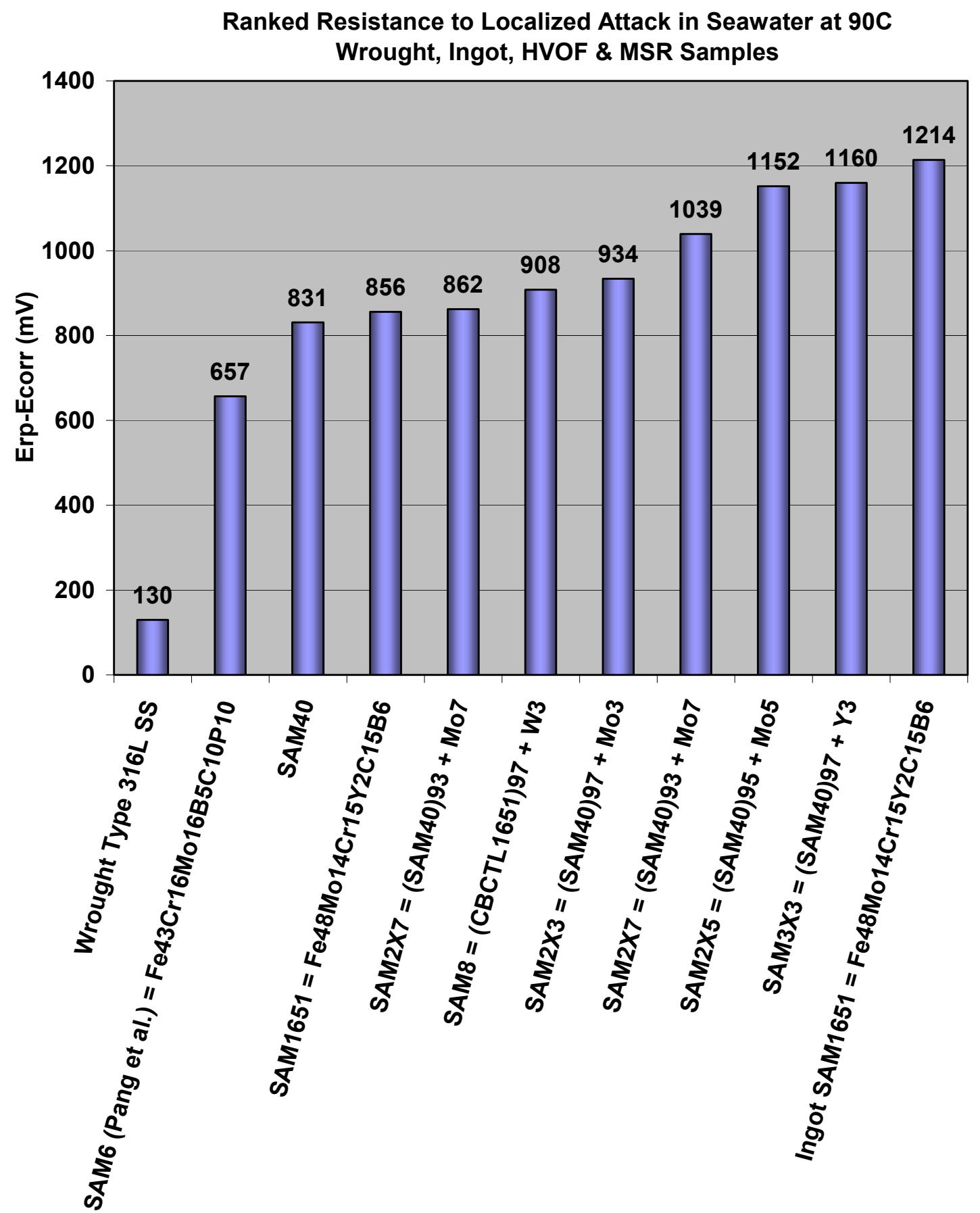

Figure 9 - Various alloy samples, ranked based upon their measured resistance to localized corrosion $(\Delta \mathrm{E}=$ $\mathrm{E}_{\mathrm{corr}}-\mathrm{E}_{\mathrm{rp}}$ ) in Half Moon Bay seawater at $90^{\circ} \mathrm{C}$. Most of the amorphous-samples performed very well, with the arcmelted drop-cast ingot of SAM1651 (also designated as SAM7) showing the best performance. The electrochemical performance of these materials in seawater was as good as Alloy C-22, and superior to Type 316L stainless steel. 

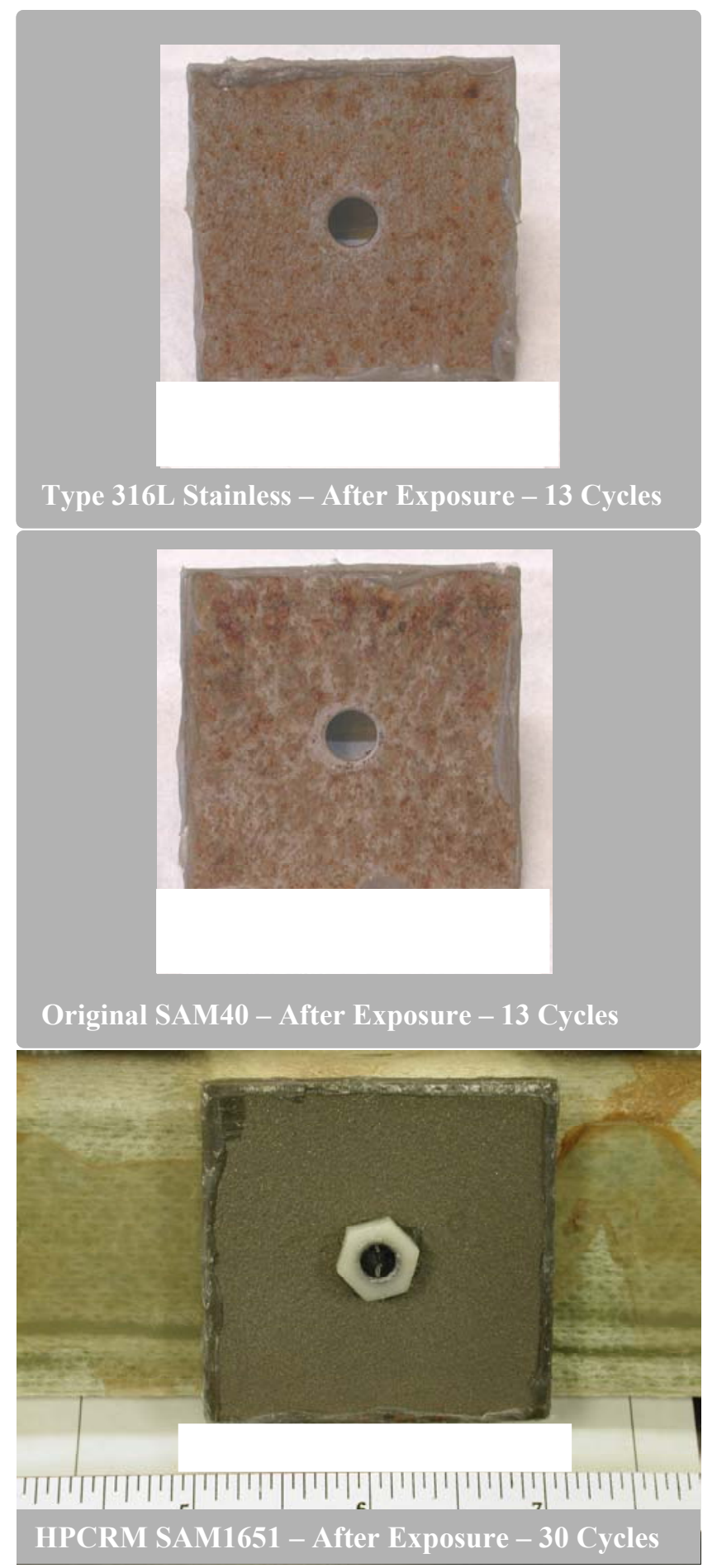

Figure 10 - Early thermal-spray coatings of Type 316L stainless steel and the SAM40 parent material showed relatively severe corrosive attack after only 13 cycles in the ASTM B117 salt fog test. However, several of the new Fe-based amorphous metal coatings, including SAM1651 and SAM2X5, have shown no corrosion, even after more than 30 cycles in this aggressive environment. It is therefore believed that these new materials will provide substantial benefit in some Naval applications. 


\section{American Society of Mechanical Engineers Pressure Vessels \& Piping (PVP) Conference - July 2005}

\section{SUMMARY AND CONCLUSIONS}

Ingots and melt-spun ribbons of the Y- and Mocontaining $\mathrm{Fe}$-based amorphous metals have no grain boundaries, and therefore have more corrosion resistance in than the more expensive nickel-based Alloy C-22. While the passive film on nickel-based $\mathrm{C}-22$ undergoes catastrophic breakdown in $5 \mathrm{M} \mathrm{CaCl}_{2}$ at $105^{\circ} \mathrm{C}$ at low potential, the passive film on the new Fe-based amorphous metal remains stable at a potential above that required for oxygen evolution.

Electrochemical tests have proven that corrosion performance superior to wrought and thermally sprayed coatings of nickel-based Alloy C-22 can be achieved with the new iron-based amorphous metals. For example, the passive film on wrought Alloy C-22 undergoes breakdown at 100 to $200 \mathrm{mV}$ vs. $\mathrm{Ag} / \mathrm{AgCl}$ in $5 \mathrm{M} \mathrm{CaCl}_{2}$ at $105^{\circ} \mathrm{C}$, whereas SAM1651 maintains stable passivity, even as the potential is increased to levels approaching that required for oxygen evolution. These materials are far superior to thermal-spray coatings of Alloy C-22 in seawater. While it has not been possible to render Alloy C-22 as a corrosion resistant, thermal spray coating, such possibilities do exist with the amorphous metal formulations.

These novel materials can be produced as either bulk alloys or coatings. For example, melt spinning and arc melting with drop casting can be used to render these materials as fully dense pore-free bulk alloys. Coatings can be produced with advanced thermal spray processes, or by physical vapor deposition processes such as magnetron sputtering or electron-beam evaporation. The materials can also be rendered as bulk alloys by using HVOF to form large plates on a flat mandrel. Near theoretical density is achieved through precise control of powder size with atomization and classification.

The current Fe-based amorphous metals include specific elements known to impart corrosion and oxidation resistance, such as $\mathrm{Cr}$, Mo, W. Additions of $\mathrm{Y}$ and $\mathrm{Zr}$ improve glass formability, while forming protective oxide scales at high temperature. In the future, the addition of titanium may also lead improved passive film stability at higher temperatures, and is being explored.

Early HVOF coatings of SAM35, SAM40, SAM40X3 had non-optimal elemental compositions, and were produced with non-optimal thermal spray parameters (powder size, gun pressure, and particle velocity), and exhibited light rusting after 13 cycles in the classic salt fog test. However, additional work with optimized elemental compositions of these Febased amorphous metals, and samples in the form of fully dense pore-free materials, have shown no corrosion after 24 cycles in this aggressive test. The most promising formulations at the present time are believed to be SAM2X5 and SAM1651. Salt-fog testing of HVOF coatings of these materials showed no corrosion after more than 30 cycles in the salt fog test. Such performance cannot be achieved with thermally sprayed Type 316L stainless steel, as this material loses most of its desirable corrosionresistance during the thermal spray process. To a lesser extent, similar difficulties are encountered during the thermal spraying of Alloy C-22.

\section{ACKNOWLEDGEMENTS}

Work was sponsored by the Defense Advanced Projects Agency (DARPA) Defense Science Office (DSO), and the United States Department of Energy (DOE) Office of Civilian and Radioactive Waste Management (OCRWM). This work was done under the auspices of the U.S. DOE by Lawrence Livermore National Laboratory (LLNL) under Contract No. W-7405-Eng-48.

The HPCRM Team expresses their gratitude to sponsors for financial support, and supportive colleagues for making this work possible. A special thanks to Dr. Leo Christodoulou (DARPA DSO) for sharing his insight and knowledge in field of materials science, and for his innovative solutions to many of the technical problems that have been addressed. Professor Joe Payer and Jef Walker (DOE OCRWM) are also gratefully acknowledged, and have helped the HPCRM Team reach the level of scientific and technical success that is now enjoyed.

\section{REFERENCES}

ASTM 1989. Designation G 5-87, Annual Book of ASTM Standards, Section 3, Vol. 3.02, pp. 79-85 (1989).

A. I. Asphahani, Materials Performance, Vol. 19, No. 12, pp. 33-43 (1980).

D. J. Branagan, M. C. Marshall, Be. E. Meacham, E. J. Buffa, High-Performance Iron-Based HVOF Amorphous Coatings, Submission to Lawrence Livermore National Laboratory for HPCRM Annual Report, NanoSteel Company, Idaho Falls, Idaho, 46 pages, September 17 (2004).

J. C. Farmer et al., Proc. 2000 ASME Pressure Vessel and Piping Conference, Seattle, Washington, July 23-27, 2000, Transportation, Storage, and Disposal of Radioactive Materials, American Society of Mechanical Engineers, PVP Vol. 408, pp. 53-70 (2000).

J. C. Farmer et al., Proc. 2000 ASME Pressure Vessel and Piping Conference, Seattle, Washington, July 23-27, 2000, Transportation, Storage, and Disposal of Radioactive Materials, American Society of Mechanical Engineers, PVP Vol. 408, pp. 71-81 (2000). 


\section{American Society of Mechanical Engineers \\ Pressure Vessels \& Piping (PVP) Conference - July 2005}

J. C. Farmer et al., Proc. Global 2003, New Orleans, Louisiana, American Nuclear Society (2003).

J. C. Farmer, J. J. Haslam, S. D. Day, D. J. Branagan, M. C. Marshall, B. E. Mecham, E. J. Buffa, C. A. Bue, J. D. K. Rivard, D. C. Harper, M. B. Beardsley, D. T. Weaver, L. F. Aprigliano, L. Kohler, R. Bayles, E. J. Lemieux, T. M. Wolejsza, N. Yang, G. Lucadamo, J. H. Perepezko, K. Hildal, L. Kaufman, A. H. Heuere, F. Ernst, G. M. Michal, H. Kahn, E. J. Lavernia, High-Performance CorrosionResistant Materials: Iron-Based Amorphous-Metal Thermal-Spray Coatings, High-Performance Corrosion-Resistant Materials (HPCRM) Annual Report, UCRL-TR-206717, Lawrence Livermore National Laboratory, Livermore, California, 178 pages, September 28 (2004).

F. Guo, S. J. Poon, Applied Physics Letters, 83 (13) 2575-2577 (2003).

L. Kaufman, Calculation of Coating Compositions for Use in Various Corrosive Environments with Pourbaix and Thermal Stability Diagrams, Massachusetts Institute of Technology, Submission to Lawrence Livermore National Laboratory for HPCRM Annual Report, Cambridge, Massachusetts, 38 pages, September 8 (2004).

R. M. Latanison, Workshop on Amorphous

Metals and Semiconductors, EPRI, May 12-18 (1985).

S. J. Pang, T. Zhang, K. Asami, A. Inoue, Acta Materialia 50, 489-497 (2002).

S. Pang, T. Zhang, K. Asami, A. Inoue, Materials Transactions, 43 (8) 2137-2142 (2002).

J. H. Perepezko, K. Hildal, Thermal and Kinetic Analysis of Amorphous Fe-Based Alloys for Use in Thermal Spray Processing, Submission to Lawrence Livermore National Laboratory for HPCRM Annual Report, University of Wisconsin, Madison, Wisconsin, 74 pages, September 9 (2004).

N. Yang, J. Farmer, G. Lucadamo, J. Haslam, Microstructual Factors and Their Implication to Corrosion and Damage Tolerance of Fe-Cr-Mo Based SAM40 and SAM1651, Submission to Lawrence Livermore National Laboratory for HPCRM Annual Report, Sandia National Laboratory, Livermore, California, August 30, 2004, 43 pages. 